\title{
“(PARA ENFRENTAR O EXTREMISMO POLÍTICO) AS PESSOAS PRECISAM SER ESPERTAS, NOTAR A PROPAGANDA E ENXERGAR OS PROBLEMAS PARA ALÉM DESTAS DICOTOMIAS E MANIPULAÇõES FÁCEIS".
}

\author{
Entrevista com Christian Picciolini
}

\section{Revista Malala (RM)}

Podemos começar com você nos contando mais sobre seu trabalho. Você escreveu um livro contanto sua história, tem uma Organização, a Life after Hate, e participa do programa ExitUSA. Qual a proposta do seu trabalho? Como você trabalha?

\section{Christian Picciolini (CP):}

Em 2009 eu fui o co-fundador de uma organização chamada "Life after Hate" que basicamente ajuda as pessoas que queiram sair de grupos e organizações de ódio, que querem se livrar de ideologias de ódio. Nós nos sentimos qualificados para fazer este trabalho por termos sido extremistas e participado destes tipos de grupos há muitos anos atrás. Eu particularmente tenho dedicado os últimos 20 anos a tentar ajudar quem quer sair e a desmontar, desmantelar estes tipos de organização que, de certa forma, eu ajudei a criar nos anos 1980 até meados dos anos 90. Somos a única organização nos Estados Unidos e na América Latina que trabalha visando o desengajamento das pessoas ligadas ao extremismo político e ideológico, em outras palavras, de pessoas ligadas a grupos de ódio. Não trabalhamos sozinhos, temos um time de psicólogos e outros profissionais que criam um trabalho multidisciplinar, tendo assim, criado uma forma de ajudar as pessoas que estão iludidas e cercadas pelo ódio. Isso tem sido um trabalho cotidiano desde 2009. Escrevi um livro contando minha história e minha vida, o livro chama-se Suástica Yankee: Memórias de um Ex-Skinhead Neonazista.

0 que nós fizemos foi construir nos últimos 8 anos uma rede com mais de 100 exmilitantes extremistas de extrema-direita e que agora estão ajudando outras pessoas com sua resiliência e enfrentando o racismo.

\section{RM}

E possível desradicalizar uma pessoa?

\section{$\mathbf{C P}$}

Não chamamos o que fazemos de "desradicalização". Nós não focamos na ideologia da pessoa. Quando eu trabalho com alguém eu não entro no mérito ideológico, eu não discuto ideologia como quem crê que "o que ele acredita é errado". 0 que eu faço é escutar. Eu escuto com o máximo de atenção possível. 0 que acontece neste processo é que eu encontro o que chamo de "buracos". Estes "buracos" aparecem nas trajetórias destas pessoas e as forçam, as levam a outros caminhos. Algumas vezes estes "buracos" podem ser, por exemplo, ficar desempregado, pode ser um gap na educação formal, pode ser uma doença mental, ou pode ser um conjunto de fatores que aconteceram com aquela pessoa e a colocam para baixo, a deixaram sem perspectiva e a levam a se tornar um extremista ou a tornar-se uma pessoa que propaga o ódio. Meu trabalho é, digamos, de "pavimentar estes buracos", tornando as pessoas mais resilientes. Assim eles podem ter mais confiança, 


\section{entrevista}

podem se qualificar para empregos, podem voltar a estudar, e assim lá na frente encontrar o que os levou ao ódio e entender que entre os que odeiam e os que são vítimas do ódio há mais similaridades do que diferenças. Uma das coisas importantes que faço é em algum momento introduzir esta pessoa que está deixando o ódio ao objeto de sua raiva e de seu ódio. Na maioria dos casos, eu noto que esta interação nunca aconteceu antes. Eles nunca tiveram uma conversa de fato com as pessoas que odeiam. Então parte do processo é "construir pontes". E é um processo interessante porque uma vez que a pessoa ganha confiança, se sente mais segura, e mais resiliente. 0 ódio muitas vezes desaparece por que havia apenas uma "ideia" para se apegar e odiar e culpar outros pelos problemas que passavam em suas vidas.

\section{RM}

Há uma trajetória que seja comum às pessoas que entram em grupos e movimentos de ódio?

\section{CP}

De forma geral, eu noto que as pessoas que entram em grupos extremistas ou que passam a defender ideologias extremistas o fazem por três motivos. São três fundamentos básicos que qualquer ser humano precisa para ter uma vida social saudável. Um deles é a busca por uma identidade. 0 outro é a busca por uma comunidade. Algo como "quem é minha família?". E o terceiro motivo é a busca por um propósito. É um pouco a busca por "querer mudar o mundo" ou querer fazer do mundo um "lugar melhor". Estes três elementos aparecem em algum ponto da vida de um extremista, e o que acontece é que se você tem uma pessoa marginalizada, uma pessoa que tem inveja, que tem um subemprego, ou que passou ou está passando por um trauma - e se está em busca destes três pontos - é fácil encontrar alguém que cruze o caminho desta pessoa e a ofereça uma "narrativa", que tende a ser bem egoísta, e que aparentemente resolve todos os seus problemas, mesmo que temporariamente. Mas, claro, não a solução para o longo prazo. Sempre se cai na lógica do "nós contra eles", colocando a culpa em "alguém" ou "grupo" e, assim, se remove a culpa e a dor e a transfere para outro.

Quando se odeia alguém ou de forma generalizada, é porque eu primeiro me odeio. É o exercício de tirar a dor e a culpa de mim mesmo e projetar num outro e, assim, eu não preciso mais ter que lidar com isso.

\section{$\mathbf{R M}$}

Como você avalia o papel das religiões na manipulação do discurso de ódio?

\section{CP}

Nem sempre grupos religiosos transformam pessoas em propagadores de ódio. Há pessoas religiosas que usam a religião para degradar, diminuir, e colocam a religião a serviço de uma ideologia egoísta, esquecendo-se que as religiões são sobre compaixão e empatia. Todas as religiões se baseiam neste princípio. Mas quando isso vira algo distorcido, cria-se a ilusão de pureza e aí se argumenta que é preciso lutar e defender um fundamento puro das religiões, e que isso pode ser perdido se não for protegido. Este é o discurso de grupos fundamentalistas, vale para o Estado Islâmico, como vale para grupos cristãos, assim como para o Ku Klux Klan (KKK), que pegam ideias e símbolos religiosos e criam um discurso próprio, apadrinhando e apropriando-se até conseguir preencher seu ego, alimentando cada vez mais um discurso egoísta. Usando a lógica "nós contra eles" até não 
poder mais, até o extremo, eles esquecem totalmente das ideias de empatia e compaixão que estão na base de qualquer religião.

\section{RM}

Há um contexto psicossocial recorrente? Como desilusão, problemas com raiva, casos de violência doméstica etc.?

\section{CP}

Em muitos casos há a recorrência de um trauma. Ou então algum tipo de distúrbio mental. Isso afeta o indivíduo e pode, de repente, torná-lo extremamente focado na busca por algo, por respostas ou por soluções. No meu caso pessoal, por exemplo, meu trauma foi sentir-me abandonado. Eu me sentia abandonado pelos meus pais que trabalhavam muito e não estavam lá comigo em minha infância / juventude. Então eu fui buscar por minha família em outro lugar. Quando as pessoas buscam ideologias extremistas, não é a ideologia que as satisfazem, é o senso de comunidade, de pertencimento e de propósito. E isso cria uma identidade.

\section{RM}

Como diferenciar os chamados "lobos solitários" daqueles que se aproximam e eventualmente entram num grupo já constituído como o KKK ou um grupo de skinheads? São casos que exigem abordagens distintas?

\section{$\mathbf{C P}$}

No caso dos "lobos solitários", muitas vezes a radicalização aconteceu online (via internet). E pode ser um recrutamento pessoal, mas muitas vezes tem a ver com sites de notícias falsas. A pessoa é bombardeada por informações confusas, falsas e sensacionalistas. Elas acabam acreditando nestas notícias falsas e se radicalizam assim. Mas há também comunidades online de ódio que estão ali prontas para se comunicar com os interessados. Estas comunidades criam uma realidade virtual identitária que só existe online, eles não conseguem reproduzir isso no mundo real, mas pressionam o individuo que se aproxima e demonstra interesse. Então estas comunidades online, mais as notícias falsas, criam neste indivíduo o senso de desespero, ao mesmo tempo em que criam uma base identitária e projetam ideais como de um "super homem", uma persona criada no mundo virtual que os leva a cometer ataques e terrorismo no mundo real. Desde o caso Dylann Roof até casos de ataques a mesquitas ou mais recentemente na cidade de Nova Iorque - quando um homem negro foi esfaqueado por um jovem branco que disse a polícia que estava ali para matar negros - todos estes casos tem em comum a tendência de radicalização via internet. Então, por mais que os ataques sejam solitários, eles foram radicalizados num contexto de comunidade, mesmo que seja uma comunidade virtual.

\section{RM}

E no caso dos líderes? Como você trabalha com as lideranças destes movimentos extremistas? Eles geralmente são carismáticos e oportunistas, sabem manipular diferentes sentimentos, seja de "vitima", seja de "liderança intelectual".

\section{CP}

Não é tão diferente como possa parecer. Os líderes são movidos por uma busca e senso de poder. Isso se destaca mais que o senso de pertencimento ou de comunidade/iden- 
tidade. 0 processo de envolvimento nestes casos não é diferente. Buscamos entender as suas necessidades, identificando os "buracos" e tentando "pavimentar o caminho". Muitas vezes o que os torna "líderes" é o fator carisma. São carismáticos, mostram-se confiantes por que já foram inseguros no passado. Nosso objetivo é buscar entender o que se passou, e as mudanças nestes casos não diferem de outros casos.

\section{RM}

E o fator gênero? Há mais homens que mulheres nos movimentos extremistas. Como as mulheres são vistas e eventualmente recrutadas?

\section{CP}

Movimentos extremistas, sejam eles de supremacia racial, neonazistas ou islâmicos, são movimentos tipicamente misóginos. É um ambiente dominado pelos homens, mas em alguns casos há um discurso que coloca a mulher como a "salvação". Ela é a "salvação" por ser "a mãe". Mas no cotidiano a forma como eles tratam as mulheres é hierárquica, as mulheres são de $2^{\underline{a}}$ classe, são misóginos. 0 suposto "respeito às mulheres" que muitos dizem ter, e que aparece em muitos discursos, definitivamente não aparece na prática. Em termos de representação, eu diria que entre extremistas os homens chegam a algo entre $80 \%$ e $90 \%$. Algo que notamos como uma tendência é a tentativa de usar as mulheres e as colocar para "falar em nome do movimento". Há muita propaganda extremista com mulheres. Isso acontece por que eles perceberam que este tipo de propaganda tem mais resposta, sempre tendo como alvo chamar atenção e recrutar outros homens. Com mulheres atraentes a ideia é atrair mais homens aos grupos extremistas.

\section{$\mathbf{R M}$}

Há alianças entre movimentos extremistas? Como são as relações de aliança entre movimentos de ódio e extremistas?

\section{CP}

Sim, há uma tendência a alianças. Não importa muito que tipo de "supremacia" se acredita, pode ser da linha "direita alternativa", "neonazista" ou "KKK", basicamente eles querem a mesma coisa: uma nação racialmente branca e, como dizem, "defender a raça branca da extinção". Eles acreditam que a ideia de "diversidade" não passa de um código para genocídio. Eles acreditam que quanto mais diversidade existir no mundo, menos espaço haverá para a cultura branca - entendida em termos de uma hierarquia racial e social. Portanto, eles são muito sensíveis e temerosos, eles se protegem nestes termos. Assim, o que os une é este inimigo comum (e isso permite alianças), é este sentimento de "ameaça racial" e de desprezo pela diversidade, abrindo espaço também para o surgimento do desprezo à cultura judaica. Há outros inimigos, mas o recorrente entre grupos extremistas é ter como inimigo comum os judeus. Por isso que eu há muitos anos atrás já previa que haveria uma ligação entre grupos de extrema direita e os jihadistas do islamismo, especialmente no Oriente Médio. Eles podem não se gostar muito, mas são unidos por um inimigo comum.

O inimigo comum pode ser mais forte que os problemas e diferenças que existam entre os grupos. Tudo isso também é alimentado por teorias conspiratórias. Ideias como as que os judeus controlam a mídia, controlam os bancos, controlam o sistema financeiro etc. Este estereótipo do inimigo judeu é alimentando pela propaganda destes grupos. E acrescente a isso as "notícias falsas" e você terá uma grande teoria conspiratória. 


\section{RM}

0 antissemitismo também tem certo apelo à esquerda. A ideia de que em última instância os judeus estão por trás do capitalismo e são responsáveis pela desigualdade tem força no eleitorado de esquerda. Na Europa, alguns movimentos totalitários tentam recrutar também militantes de esquerda. Como você avalia esta tática?

\section{CP}

Se você pensar no espectro ideológico na política, ele pode ser circular. Numa ponta você teria a extrema direita e na outra ponta a extrema esquerda. Quanto mais em direção ao "extremo" se for, maior a chance da "esquerda" e da "direita" se encontrarem. Notam-se táticas similares, o pensamento limitado, a manipulação do medo, e também quanto mais ao extremo mais comum e fortes são as narrativas conspiratórias. Extremismos tanto de direita ou de esquerda - não importa - não são bons. O desafio é encontrar uma base comum, resgatar o centro, onde todos podem ser respeitados e se tratarão com respeito, onde as opiniões importam e se trabalha para que todos tenham os mesmo direitos e justiça. Isso é melhor que a polarização que vivemos, na qual um tenta "calar a boca" do outro e acha que sua visão é melhor.

\section{RM}

Como você avalia a campanha e as ideias de Donald J. Trump?

\section{CP}

É difícil analisar o que a campanha de Trump produziu. A Direita Alternativa de repente estava em todos os lugares e Trump criou um movimento nacional. Em certo ponto é como se ele jamais pudesse estar errado independentemente do que ele dizia ou fazia. Mesmo sendo pouco consistente, digamos assim, como a verdade, ele criou um movimento. Trump surge como alguém que fala para e em nome de uma parcela da população dos EUA que reclamava não estar sendo ouvida. E eles votaram em Trump. Eu particularmente não dou a Trump o "beneficio da dúvida". Falo isso porque se você analisar o que ele disse, seja sobre migração, seja sobre as mulheres, sobre a ideia de "barrar a entrada de imigrantes e refugiados de países muçulmanos", seria perigoso esperar que estas ideias virassem políticas de governo. Ele apresenta estas ideias como se fosse patriota, mas eu acho que são ideias antiamericanas. Uma das ideias mais básicas em torno dos EUA como nação é a imigração. Os EUA foi construído como nação de imigrantes e isso está na base de nossos valores, então para mim negar isso é antipatriótico.

Trump na campanha se dirigiu a uma população que se dizia excluída do debate político e prometeu o que eles queriam ouvir. Mais do que entregar, Trump enfatiza a retórica, a ideia de dizer e ser a "voz" desta nova base eleitoral. Por isso agora como presidente, quando é preciso entregar alguma coisa, Trump tem fracassado.

\section{RM}

E a Direita Alternativa? Ela surge como uma voz nacionalista também "esquecida" ou silenciada na política americana?

\section{CP}

Sim. Muitos que formaram o gabinete de Trump foram ou ainda são ligados a Direita Alternativa. Eu posso te dizer que se fosse há 30 anos, quando eu estava militando 
na extrema direita, eu ficaria bastante empolgado com Donald Trump. As coisas que ele diz, promete, e os seguidores que conquistou, deixariam qualquer extremista americano bastante animado. Suas falas, mesmo que confusas, sobre imigração, raça e religião, soam nacionalistas e isolacionistas, e o mesmo se aplica a seus movimentos e tendências para a política externa. Tudo isso deixaria uma pessoa como eu, quando era do movimento, bastante esperançosa. Tudo que eu queria naquela época era a ideia de uma "América para Brancos", e se formos à essência do que ele está dizendo hoje, não é muito diferente disso.

Agora, mesmo com o empoderamento da Direita Alternativa, há frustrações aumentando. Há muitas coisas que Trump não poderá cumprir e os efeitos disso são imprevisíveis.

\section{$\mathbf{R M}$}

Trump se defende muito com o argumento do "politicamente correto". Quando acuado, ele costuma responder desqualificando a crítica como sendo "politicamente correta". Tenho a impressão que é a mesma estratégia tanto da Direita Alternativa quanto dos grupos de ódio, não?

\section{CP}

Sim, claro. Trump argumenta que nos tornamos muito "politicamente corretos" (PC), que há uma tentativa de regular como pensamos e como nos manifestamos. Algo diferente disso é o que entendo como um movimento cuja ideia é ser mais consciente de como as pessoas se sentem - não sei se deveríamos classificar isso como "politicamente correto", mas talvez isso faça parte de sermos simplesmente seres humanos mais decentes. Mas eu também entendo a visão dos que criticam uma ideia de "politicamente correto". De fato, em nome do "politicamente correto", alguns debates duros e difíceis não aconteceram e não estão acontecendo, então algumas conversas precisam ocorrer e o medo de ferir os sentimentos de alguém não poderia ser motivo para impedir o debate. 0 desafio é achar um ponto de equilíbrio e identificar o que de fato é mero "politicamente correto" e o que é preconceito, racismo etc. Este debate é importante porque há argumentos fortes em ambos os lados, tanto entre os que criticam o PC como entre os que querem combater a linguagem preconceituosa e o discurso de ódio.

\section{RM}

Gostaria de voltar à discussão sobre o antissemitismo que fizemos há pouco. Você mencionou que isso é comum tanto nos discursos jihadistas como dos grupos de ódio da extrema direita. No caso do Oriente Médio e Mundo Muçulmano, incluindo o conflito Israel-Palestina, o problema histórico do antissemitismo é recorrente. Há alguma saída?

\section{CP}

Este problema já ocorre há séculos. Não há uma resposta simples. 0 que eu proponho é que estejamos mais conectados uns com os outros. Isso ocorre através da compaixão. Eu mudei por que pessoas com as quais eu não tinha compaixão nenhuma mostram compaixão por mim nos momentos mais difíceis, momentos que não merecia nenhuma compaixão. Se olharmos para as relações entre árabes e judeus, é difícil argumentar por uma solução simples. Se eu for trabalhar com um caso de um radical árabe antissemita eu usaria a mesma metodologia de trabalho que aplico num militante de extrema direita, também antissemita. 0 ponto seria ligá-los ao objeto de seu ódio de forma a humanizar este "outro odiado", e assim retirar este preconceito que está em sua cabeça. Na prática, o 
recorrente é que estas pessoas cheias de ódio nunca tiveram contato ou qualquer interação com seu objeto de ódio.

\section{RM}

Alguns autores como Patrick Buchanan tentam escrever, ou melhor, reescrever a história apresentando uma narrativa na qual os árabes seriam muito mais fortes e poderosos que os judeus. Segue um pouco na linha da tradição autores que negam o holocausto. Já outros tantos autores apelam para a islamofobia, falam dos perigos do islã etc. No fundo são dois lados lutando por um mesmo público? Como você vê e diferencia isso?

\section{$\mathbf{C P}$}

Não vejo muita diferença. É a ideia de um grupo contra o outro, criando generalizações. É a ideia de que um grupo sempre está contra o outro. Isso funciona como um clássico caso de propaganda. As pessoas precisam ser espertas, notar a propaganda e enxergar os problemas para além destas dicotomias e manipulações fáceis. Não podemos julgar bilhões de muçulmanos por aquilo que um grupo faz, assim como não podemos julgar os bilhões de cristãos mundo a fora com base, por exemplo, no KKK. E a mesma coisa em se tratando dos judeus. Não podemos dizer algo sobre o grupo com base em eventualmente uma (boa ou má) experiência pessoal. É ridículo achar que uma pessoa pode representar o grupo, seja ela judia, cristã ou muçulmana. E todos aqueles que querem revisar a história ou que tentam retratar um grupo ou uma religião de forma simplista e maniqueísta, está agindo provavelmente motivado pelo seu próprio ego ou interessado numa agenda política, e não interessado ou buscando a verdade.

\section{RM \\ Você já trabalhou ou teve contato com um radical islâmico? \\ CP}

Eu estive em Bruxelas na Bélgica - neste ano - divulgando meu livro e tive oportunidade de conhecer um ex-combatente e militante do Estado Islâmico, que lutou na Síria e agora estava morando na Bélgica. Ele já esteve preso inclusive. Depois de minha fala ele me procurou e conversamos. Ele me contou que se sentia como uma pessoa sem par, no sentido de ser uma pessoa que mudou, que deixou o radicalismo. Ele reclamava de solidão. Eu contei minha história e ele contou a dele. No final, chegamos à conclusão de que éramos parecidos, que tínhamos histórias similares. Nós dois entramos em movimentos extremistas não por uma questão ideológica, mas buscando outras coisas, como identidade, senso de comunidade e um propósito. Então no final das contas percebi que o que fazemos para retirar militantes da extrema direita nos EUA funcionaria para retirar muçulmanos do jihadismo.

\section{RM}

Para encerrar, nos conte como está a recepção do livro no Brasil. Como tem sido as reações? Tem planos de vir pra cá?

\section{CP}

O livro foi lançado há alguns meses, tenho a impressão que está indo bem. Recebi várias respostas e feedbacks de leitores. É interessante notar que o que conto no livro gera uma identificação em muitos brasileiros. No Brasil há pobreza, divisão de classe etc., mas há também racismo. E há um problema com a extrema direita e com a violência. Eu 
escrevi o livro para aqueles que buscam um relato honesto de como um "bom menino" acabou fazendo "coisas ruins" durante muitos anos de sua vida. Isso mostra que a radicalização pode acontecer com qualquer pessoa, seja pobre, classe média ou elite. Pode ser alguém de uma família bem estruturada ou de uma família desajustada. A questão é que quando buscamos certas coisas, certos propósitos, nos tornamos vulneráveis e podemos ser assim facilmente interceptados e recrutados. Portanto, espero que meus leitores no Brasil, ao lerem minha história, possam se identificar e ampliar sua visão sobre este tema tão sensível e perigoso.

\section{RM}

Muito obrigado pela entrevista.

\section{CP}

Obrigado, foi um prazer. Eu adoraria visitar o Brasil. Não tenho nada certo pra já, mas espero ainda neste ano fazer uma visita. 